\title{
Social trust, workplace organization, and the comparative advantage of nations
}

\section{By André van Hoorn}

Radboud University, Institute for Management Research, PO Box 9108, 6500 HK, Nijmegen, The Netherlands; e-mail: A.van.Hoorn@fm.ru.nl

\begin{abstract}
In this paper, I consider a specific channel through which trust between parties to an exchange can go on to affect nations' comparative advantage in certain industries. My approach revolves around the autonomy that employers (principals) grant to workers (agents), which is a key feature of workplace organization. I hypothesize that social trust generates a comparative advantage in industries with more autonomous micro production environments. I employ individual-level data on work autonomy to construct a measure of the extent to which industries are characterized by autonomy in the production process. Results of a cross-country cross-industry analysis confirm that countries with higher levels of social trust have a comparative advantage in high-autonomy industries and vice versa. Results are robust to the possibility of reverse causality. The paper's key contribution is to provide a link between the microeconomic literature on workplace organization and the comparative macroeconomic literature on social trust.
\end{abstract}

JEL classifications: D23, L23, M54, 043, 057, P50.

\section{Introduction}

Social trust, which can be defined simply as a societal norm of cooperation, provides the basis for collective action and is linked to uncertainty reduction and lower transaction costs in economic exchange (Arrow, 1972; Gambetta, 1988; Fukuyama, 1995). As an informal enforcement mechanism, social trust allows exchange relationships to exist and extend beyond kinship-based communities, in turn sustaining a more fine-grained division of labour and increased specialization (Fukuyama, 1995). The macro-level implications of social trust-promoting economic prosperity and fostering other beneficial societal outcomesare thus well understood (Beugelsdijk et al., 2004; Algan and Cahuc, 2010). Moreover, the basic logic underlying these positive effects of social trust-running through enforcement, transaction costs, and the division of labour-is also clear.

However, extant research has narrowly focused on relationships between macro-level variables and does not consider how exactly trust between two or more parties to an exchange goes on to affect economies in the aggregate. Whilst lower transaction costs and 
uncertainty reduction are intuitively appealing promoters of economic exchange at the micro level, little attention has been paid to the connection between the micro level at which social trust operates and trust's effect on economic outcomes at the macro level. This paper seeks to contribute to the comparative macroeconomic literature on social trust by considering such a connection. Specifically, this paper works on developing and testing a micro-level channel through which social trust affects nations' comparative advantage. To do so, I combine two important developing research areas, one at the micro level and one at the macro level.

First, a growing literature considers workplace organization or organizational design to account for firm-level differences in performance and productivity (see Bloom et al., 2014 for a review). I expand on earlier work to consider work autonomy instead of more narrow and concrete human resource management practices. ${ }^{1}$ Second, researchers have started to use cross-country cross-industry analysis to study domestic institutions as determinants of comparative advantage, especially of industry export flows (see Nunn and Trefler, 2013 and Ciccone and Papaioannou, 2016, for reviews). The idea in this literature is that the institutions in a country can be an endowment in much the same way that traditional production factors such as labour and capital are. In particular, the relative strength or weakness of certain institutions in a country would lead this country to have a comparative advantage in certain types of activities or industries. Earlier cross-country cross-industry studies of countries' comparative advantage focused on the role of formal institutions. Manova (2008, 2013), for instance, finds that countries with a well-developed financial system have a comparative advantage in capital-intensive industries. I follow-up with a cross-country cross-industry analysis that considers social trust as a key informal institutional endowment. $^{2}$

Following the standard approach in the literature (Romalis, 2004; Nunn and Trefler, 2013), an essential feature of my cross-country cross-industry analysis is the benchmarking of industries. Whereas capital or labour intensity are standard industry benchmarks, my concern with social trust and workplace organization means that I characterize the organization of work in a particular industry based on the level of autonomy granted to employees in this industry. Trust operates at the micro level where it governs interactions between economic actors. Hence, by considering the level of work autonomy that principals grant to their agents, I am able to construct an industry measure that embodies microlevel evidence on a vital form of exchange between two parties. Many papers in the literature on domestic institutions and export patterns construct industry benchmarks based on

1 My focus on work autonomy matches most closely to Bloom et al.'s (2012) firm-level analysis relating trust to decentralization in multinational firms. More generally, several studies show that social trust has a positive effect on the level of autonomy granted to employees (Van Hoorn, 2013; Gur and Bjørnskov, 2016). Figure A.1 in the Appendix documents this positive correlation between social trust and average work autonomy in a country, using data from two of the main data sets used in this paper.

2 Tabellini (2008) and Cingano and Pinotti (2012) examine the effect of social trust on export flows from different types of industries. Compared to my work, these studies suffer several drawbacks, however. These drawbacks include biased results on the count of so-called attenuation and amplification effects (Nunn and Trefler, 2013; Ciccone and Papaioannou, 2016) and the use of blunt instrumental variables (Bazzi and Clemens, 2013) that violate the exclusion restriction (see for example Algan and Cahuc, [2013] for a discussion of violations of the exclusion restriction in social trust studies). 
industries' intermediate inputs such as capital. This paper, in contrast, employs individuallevel data, thus obtaining an industry benchmark that gives a most detailed and direct reflection of what goes on in firms within specific industries and how people in an industry work together to create added value. Empirically, the key question that I address in this paper is how social trust interacts with my industry benchmark and affects whether countries have a comparative advantage in high- or low-autonomy industries.

Workplace organization, specifically work autonomy, provides the starting point for my analysis. A straightforward definition of work autonomy is as 'the condition or quality of being self-governing or free from excessive external control' (Jermier and Michaels, 2001, p.1006). I have the following hypothesis: the stronger a country's social trust norm, the more this country has a comparative advantage in industries characterized by high levels of work autonomy in their production processes. Autonomy for workers is associated with various advantages for firms, deriving from the division of labour and specialization in the production process (Becker and Murphy, 1992). Granting specialist workers the autonomy to organize their productive activities in the way they deem fit results in a more efficient production process than when a non-specialist manager tells workers exactly what they should be doing. However, a disadvantage of giving employees freedom to perform their job in their own way is that, in the absence of monitoring and control, it can be difficult to get employees to act in the best interest of the firm, as highlighted by the classic principalagent problem. In short, for firms, work autonomy only pays off if this autonomy is accompanied by a certain amount of trust. The reason is that the presence of trust implies that the principal is justified in relying on the agent to foster the principal's interests despite a lack of formal incentives. In contrast, if trust is absent, costs due to shirking are likely to outweigh the benefits of having expert workers that can leverage tacit skills and uncodified knowledge. The effect of social trust that matters here is therefore not so much about beliefs that employers have about their workers, but about how workers will behave when granted a certain amount of autonomy. Aggregating the above logic of trust as a form of cooperation, I expect that industries characterized by highly autonomous work environments will flourish in high-trust societies, whilst these industries will struggle in low-trust societies. More specifically, I expect that social trust acts as an institutional endowment so that countries with strong societal trust norms will have a comparative advantage in industries with more autonomous work environments as for these industries social trust is a relatively more important endowment. Overall, the theoretical rationale for my hypothesis thus follows the standard logic of comparative advantage and relative factor abundance: countries will have a comparative advantage in those industries for which their informal institutional endowments provide a useful resource for firms active in these industries and vice versa. ${ }^{3}$

To test my hypothesis, I use the standard cross-country cross-industry estimating equation for comparative advantage (e.g. Romalis, 2004). This means that I interact my measure of social trust with the industry benchmark of work autonomy, whilst controlling for country and industry fixed effects. A positive and significant coefficient for this interaction indicates that countries with higher social trust have a comparative advantage in highautonomy industries, which would confirm my hypothesis. Results provide strong support

3 Of course, the proposition that high-trust countries have a comparative advantage in highautonomy industries (and vice versa) takes in the empirical evidence showing a positive effect of social trust on work autonomy (e.g. Bloom et al., 2012; Van Hoorn, 2013; Gur and Bjørnskov, 2016; see, also, Note 1 and Fig. A.1 in the Appendix). 
for my hypothesis and are robust to a variety of checks, including the use of alternative measures of industry work autonomy. To identify whether social trust indeed causally interacts with industry work autonomy to affect countries' comparative advantage in specific industries, I build on Algan and Cahuc's (2010) analysis and use trust scores from migrants to measure the cultural component of social trust that is independent of countries' economic and institutional environment. The resulting trust indicator helps affirm that social trust causally interacts with workplace organization to shape cross-country patterns of comparative advantage. Overall, the evidence thus provides strong empirical support for the idea that social trust interacts with workplace organization to affect economies in the aggregate.

This paper, then, makes two main contributions, an empirical one and a broader, conceptual one. Extant studies of the economics of social trust leave us wondering about a specific channel through which trust between parties to an exchange affects economies in the aggregate. The basic logic-running through uncertainty reduction and lowering of transaction costs-is obvious, but lacks detailed evidence on the steps involved, particularly at the micro level, which is the level at which we expect trust to act as an informal enforcement mechanism that facilitates exchange between economic actors. My main empirical contribution subsequently is to pin down a specific channel for a key macroeconomic consequence of social trust, namely nations' comparative advantage. Starting with workplace organization at the micro level and going up all the way to comparative advantage at the macro level, this paper's empirical evidence shows how trust between two parties can go on to affect societies as whole.

The paper's broader contribution lies in connecting important research areas. Institutions, formal ones such as rule of law and informal ones such as culture and social trust, are widely recognized for having important macroeconomic consequences. Similarly, there is increasing interest in workplace organization and organizational design as key determinants of firm performance. Nevertheless, even though the development of economies as a whole is crucially driven by the activities of firms, these two literatures have mostly developed disjointedly. My paper indicates one way of integrating the two strands of research, forging the kind of connection between different levels of analysis that seems vital for better understanding a variety of macroeconomic outcomes and how these are affected by informal institutions.

\section{Autonomy as a feature of workplace organization}

\subsection{Measuring work autonomy}

Management scholars have long been interested in features of workplace organization and what workers actually experience in their jobs (e.g. Hackman and Oldham, 1975). Adam Smith's (1776) famous description of a pin factory is thereby identified as the first contribution on this topic (Oldham and Hackman, 2010). The typical approach to measuring work autonomy (or other features of workplace organization) is via surveys, specifically questionnaire items that ask respondents to report on the level of autonomy or freedom that they experience in their work. Different survey instruments are available and the most widely used instruments simply ask respondents something along the following lines: 'Using this card, please say how much the management at your work allows/allowed you to decide how your own daily work is organised.' This item is included in the European Social Survey (ESS) (Jowell and the Central Co-ordinating Team, 2007), a cross-national survey 
of some 30 Eurasian countries, and the main item that I draw on in this paper. Respondents can rate their level of work autonomy from 0, 'I have/had no influence', to 10, 'I have/had complete control'. Of course, many different item wordings are possible. The US General Social Survey (GSS) (Smith et al., 2013), for instance, presents a statement to respondents ('I am given a lot of freedom to decide how to do my own work') and offers four possible answers ('1-Not at all true', '2-Not too true', '3-Somewhat true', and '4-Very true'). ${ }^{4}$ The basic idea is always the same, however, namely that people report on their experienced level of work autonomy.

\subsection{Validity of measured work autonomy}

A concern with the typical work autonomy measure is that it is subjective, based on individuals' perceptions, which could result in biases due to non-random measurement error. Of course, work autonomy has already been much studied in management (see Jermier and Michaels, 2001, for a review). Nevertheless, to gather some explicit evidence on the validity of measured work autonomy, I adopt the standard approach to assessing construct validity in psychology, which is to check how a measured construct relates to other constructs that would theoretically relate to the construct of interest in specific ways (Cronbach and Meehl, 1955). If a construct is valid, it should exhibit logical relationships with other constructs.

Taking this approach, I find that measured work autonomy relates to a variety of other factors in a manner that provides strong validation of the construct (Table 1). Notably, managers have higher levels of work autonomy than subordinates do and the higher educated are granted more autonomy than people with lower levels of education are. In addition, levels of work autonomy relate to other perceived features of workplace organization, specifically the amount of influence people have on organizational decisions (see Van Hoorn, 2016). Overall, patterns found are precisely the patterns that we expect from valid measures of work autonomy, strongly suggesting that indicators of work autonomy indeed measure what they are supposed to measure.

\section{A measure of industry work autonomy}

In this section, I construct a measure of industry work autonomy and demonstrate the reliability of this measure. Valid measures of work autonomy offer a great opportunity to benchmark industries on the basis of the micro-level features of their work environments, in turn allowing me to establish a micro-level channel for the effect of social trust on macroeconomic outcomes.

My approach is to employ individual-level data on work autonomy and construct an industry benchmark that captures how people in specific industries work together to create value added. By nature of their production processes and how these are organized, industries may be characterized as having more or less autonomous work environments. Taking this micro-level approach, I ensure that my analysis of countries' comparative advantage in specific industries is consistent with and, in fact, strongly grounded in our understanding of trust as a factor shaping exchange relationships between economic actors.

4 For this last example, I have reverse coded the original answer categories of the item to let higher scores indicate higher levels of work autonomy. 
Table 1. Validity of the work autonomy measure

Panel A: General Social Survey (GSS) data

\begin{tabular}{|c|c|}
\hline Variable & $\begin{array}{l}\text { Mean work } \\
\text { autonomy }(1-4\end{array}$ \\
\hline \multicolumn{2}{|l|}{ Manager } \\
\hline Yes $[n=418]$ & $3.53(0.736)$ \\
\hline No $[n=743]$ & $3.31(0.856)$ \\
\hline \multicolumn{2}{|l|}{ Highest educational degree } \\
\hline Less than high school $[\mathrm{n}=405]$ & $3.35(0.859)$ \\
\hline High school $[\mathrm{n}=2346]$ & $3.33(0.864)$ \\
\hline Associate/Junior college $[\mathrm{n}=442]$ & $3.43(0.789)$ \\
\hline Bachelor's $[\mathrm{n}=933]$ & $3.44(0.751)$ \\
\hline Graduate $[\mathrm{n}=512]$ & $3.61(0.641)$ \\
\hline \multicolumn{2}{|c|}{$\begin{array}{l}\text { In your job, how often do you take part with others in } \\
\text { making decisions that affect you? }\end{array}$} \\
\hline Often $[\mathrm{n}=1907]$ & $3.58(0.658)$ \\
\hline Sometimes [n=1663] & $3.35(0.794)$ \\
\hline Rarely $[\mathrm{n}=669]$ & $3.14(0.950)$ \\
\hline Never $[\mathrm{n}=396]$ & $3.09(1.08)$ \\
\hline \multicolumn{2}{|c|}{$\begin{array}{l}\text { How often do you participate with others in helping set } \\
\text { the way things are done on your job? }\end{array}$} \\
\hline Often $[\mathrm{n}=1554]$ & $3.58(0.685)$ \\
\hline Sometimes [ $\mathrm{n}=1181]$ & $3.34(0.784)$ \\
\hline Rarely $[\mathrm{n}=461]$ & $3.12(0.909)$ \\
\hline Never $[n=277]$ & $3.00(1.11)$ \\
\hline
\end{tabular}

Panel B: International Social Survey Program (ISSP) data

Variable

Mean work

autonomy (1-3)

Manager

Yes [n $=7461]$

$2.20(0.679)$

No $[\mathrm{n}=15,652]$

$1.88(0.742)$

Education level

No formal qualification [ $\mathrm{n}=2268]$

$1.84(0.820)$

Lowest formal qualification [ $\mathrm{n}=2763$ ]

$1.95(0.807)$

Above lowest qualification [ $\mathrm{n}=4284]$

$1.96(0.753)$

Higher secondary completed $[\mathrm{n}=5315]$

$1.97(0.729)$

Above higher secondary level $[\mathrm{n}=4743]$

$2.05(0.705)$

University degree completed [ $\mathrm{n}=4879]$

$2.15(0.672)$

Applies to respondent's job: I can work independently

Strongly agree $[\mathrm{n}=6302]$

$2.33(0.694)$

Agree $[\mathrm{n}=11,088]$

$2.08(0.697)$

Neither agree nor disagree $[\mathrm{n}=2937]$

$1.71(0.657)$

Disagree $[\mathrm{n}=2854]$

$1.53(0.666)$

Strongly disagree $[\mathrm{n}=1080]$

$1.46(0.657)$

Panel C: European Social Survey (ESS) data

Variable

Mean work

autonomy (0-10)

Manager
Yes $[\mathrm{n}=42,319]$
No $[\mathrm{n}=101,836]$

$5.18(3.64)$ 
Table 1. Continued

Panel C: European Social Survey (ESS) data

Variable

Mean work

autonomy (0-10)

\section{Education (ES-ISCED)}

I, less than lower secondary [ $\mathrm{n}=6849$ ]

$4.50(3.88)$

II, lower secondary $[\mathrm{n}=14,226]$

IIIb, upper secondary, vocational or no access to V1 $[n=22,478]$

$4.65(3.80)$

IIIa, upper secondary, general and/or access to V1 [n $=17,599]$

$5.33(3.65)$

$5.77(3.48)$

IV, advanced vocational, sub-degree $[\mathrm{n}=8496]$

$6.52(3.31)$

$7.34(2.68)$

$\mathrm{V} 1$, lower tertiary education, BA level $[\mathrm{n}=9106]$

$7.42(2.69)$

Current job: can decide time start/finish work

Not at all true $[\mathrm{n}=9692]$

$4.96(3.50)$

A little true $[\mathrm{n}=3690]$

$6.33(2.93)$

Quite true $[\mathrm{n}=2852]$

$7.41(2.50)$

Very true $[\mathrm{n}=2395]$

$8.20(2.45)$

Years of schooling (seven quantiles)

Quantile 1 (4.82 years of schooling on average) [ $\mathrm{n}=14,161]$

$4.88(3.87)$

Quantile 2 ( 8.51 years of schooling on average) [ $\mathrm{n}=17,334]$

$4.94(3.81)$

Quantile 3 (10.6 years of schooling on average) $[n=25,500]$

$5.31(3.69)$

Quantile 4 (12.0 years of schooling on average) [ $n=22,967]$

$5.66(3.56)$

Quantile 5 (13.0 years of schooling on average) [ $n=13,780]$

$6.06(3.39)$

Quantile 6 (14.9 years of schooling on average) $[\mathrm{n}=29,562]$

$6.73(3.14)$

Quantile 7 (18.7 years of schooling on average) [ $\mathrm{n}=20,411]$

$7.36(2.73)$

Allowed to influence policy decisions about activities of organization (01-0)

0

1

2

3

4

5

6

7

8

9

10

I have/had no influence $[\mathrm{n}=38,206]$

$3.15(3.65)$

$[\mathrm{n}=10,697]$

$4.18(3.16)$

$[\mathrm{n}=8947]$

$5.28(2.82)$

$[\mathrm{n}=7264]$

$5.86(2.55)$

[ $\mathrm{n}=5490$ ]

$6.15(2.35)$

$[\mathrm{n}=11,206]$

$6.74(2.26)$

[ $\mathrm{n}=6869$ ]

$7.31(1.86)$

[ $\mathrm{n}=8417]$

$7.83(1.70)$

[n $=8695$ ]

$8.36(1.51)$

$[\mathrm{n}=4740]$

$8.88(1.34)$

I have/had complete control [ $\mathrm{n}=14,539]$

Notes: Number of observations in square brackets and standard deviations in parentheses, if applicable. Source: Data come from the GSS (years 2002, 2006, and 2010), the 2005 International Social Survey Program (ISSP) Module on Work Orientation (ISSP Research Group, 2013), and the ESS (Waves 1-4) (Jowell and the Central Co-ordinating Team, 2007). The ISSP measure of work autonomy asks respondents 'Which of the following statements best describes how your daily work is organized?', giving three possible answers: ' 1 - I am not free to decide how my daily work is organized', '2-I can decide how my daily work is organized, within certain limits', and ' 3 - I am free to decide how my daily work is organized'. As with the GSS item, I have reverse coded answer categories for this item so that a higher score indicates more work independence. ISCED stands for International Standard Classification of Education. The division of respondents' number of years of schooling in seven quantiles (ESS data) has been chosen to match the seven categories of ISCED. Waves from the ESS are selected to match the ESS waves that I use later to benchmark industries by their level of work autonomy. Instead of calculating mean autonomy scores, I have also estimated regression models with work autonomy as the dependent variable and the individual characteristics listed in the table as independent variables, as in Van Hoorn (2013). Results (available on request) reveal the same patterns as presented here, supporting the construct validity of the work autonomy measure. More information about the surveys used, as well as details on all questionnaire items, can be found at the websites of these surveys: http://www.europeansocialsur vey.org for the ESS, http://gss.norc.org for the GSS, and http://www.issp.org for the ISSP. 
I measure industry work autonomy using the first four waves of the cross-national ESS data set introduced in the previous section. The first four waves of the ESS have recorded respondents' industry of occupation using two-digit NACE codes (revision 1.1), for a total of 138,445 individual observations in 62 industries. ${ }^{5}$ An important feature of my industry work autonomy measure is that it comprises individual-level data from multiple countries and not just one country, as is typical in the literature. A problem for cross-country crossindustry studies is so-called benchmarking bias, which can shift estimates downwards or upwards (Nunn and Trefler, 2013; Ciccone and Papaioannou, 2016). A downward, attenuating bias occurs because the benchmarking of industries is subject to random measurement error. The upward, amplifying bias occurs because the benchmarking of industries on the basis of data from only one country (for example the US) likely results in an industry benchmark that is reminiscent of the specific institutions in this country that affect the country's industrial structure. An upward bias then occurs because the resulting industry benchmark is more accurate for countries that are institutionally more similar to the country that provided the data used for constructing the original industry benchmark. I calculate the measure of industry work autonomy using data from 30 highly institutionally diverse countries, which likely alleviates the problem of benchmarking bias. ${ }^{6}$ Nevertheless, as a robustness check, I repeat my baseline analysis using two alternatives to my main measure of industry work autonomy. For the first alternative measure, I use only individual-level data from countries that have mean levels of work autonomy below the average of the 30 countries in the ESS sample. For the second alternative measure, I use only individual-level data from countries that have mean levels of work autonomy above the average of the 30 countries in the ESS sample. Dividing the individual-level work autonomy data this way ensures that I have two samples comprising roughly the same number of individuals when calculating the alternative measures of industry work autonomy. At the end of this section, I also check the reliability of my industry work autonomy measure, which relates to the issue of random measurement error in industry benchmarks. Meanwhile, the two alternative measures of industry work autonomy correlate strongly with my main measure of industry work autonomy $(r=0.907$ for the 'below-average' measure and $r=0.895$ for the 'above-average' measure $[\mathrm{n}=21])$.

I calculate industry work autonomy as the mean level of work autonomy reported by all respondents working in a particular industry. Table 2 (Panel A) presents the results for the 24 industries for which I also have country data on comparative advantage (see the next section). Although the 24 industries are somewhat similar-none belong to the services sector-there is substantial variation in average work autonomy. Measured industry differences thereby have face validity with, for instance, the manufacture of medical, precision and optical instruments, watches and clocks involving much more autonomy in the production process than the manufacture of textiles. Furthermore, measured differences between

5 NACE codes refer to the Statistical Classification of Economic Activities developed by the statistical agency of the European Union. NACE codes match ISIC codes. I use data from the first four waves of the ESS only because the industry data from later waves of the ESS are not compatible with industry data from these earlier waves.

6 In terms of institutional diversity, these countries cover all five legal origins recognized in the literature (common law, French law, German law, socialist law, and Scandinavian law) and seven out of the 12 clusters of national culture identified by Hofstede (2001), the world's leading cross-cultural researcher (see Van Hoorn, 2016). 
Table 2. Autonomy as a feature of industries' micro work environment

Panel A: Industries included in empirical analysis

Industry (NACE classification rev. 1.1, two digits, with code in square

Industry work

brackets) autonomy benchmark

Agriculture, hunting, related service activities [1]

5.88

Forestry, logging, related service activities [2]

5.61

Fishing, fish farming and related service activities [5]

6.03

Manufacture of food products and beverages [15]

4.74

Manufacture of tobacco products [16]

4.20

Manufacture of textiles [17]

Manufacture of wearing apparel; dressing and dyeing of fur [18]

Tanning and dressing of leather [19]

4.08

Manufacture of wood and of products of wood and cork, except furniture;

4.79

manufacture of articles of straw and plaiting materials [20]

Manufacture of pulp, paper and paper products [21]

5.10

Publishing, printing and reproduction of recorded media [22]

6.42

Manufacture of coke, refined petroleum products and nuclear fuel [23]

6.09

Manufacture of chemicals and chemical products [24]

5.85

Manufacture of rubber and plastic products [25]

4.71

Manufacture of other non-metallic mineral products [26] $\quad 4.74$

Manufacture of basic metals [27]

4.78

Manufacture of machinery and equipment not elsewhere classified [29]

5.29

Manufacture of office machinery and computers [30]

6.27

5.12

Manufacture of electrical machinery and apparatus not elsewhere classified [31]

Manufacture of radio, television and communication equipment and apparatus [32]

Manufacture of medical, precision and optical instruments, watches and clocks [33]

Manufacture of motor vehicles, trailers and semi-trailers [34]

Manufacture of other transport equipment [35]

Other business activities [74]

6.66

Mean of industry means for industries included in empirical analysis $(\mathrm{n}=24)$

Panel B: Selected industries, not included in empirical analysis

Industry (NACE classification rev. 1.1, two digits, with code in square brackets)

Mining of coal and lignite, extraction of peat [10]

Hotels and restaurants [55]

Education [80]

Activities auxiliary to financial intermediation [67]

Research and development, basic research [73]
Industry work

autonomy benchmark

Notes. Data are author's calculations based on data from Waves 1-4 of the ESS, which have been held bi-annually in 2002, 2004, 2006, and 2008. 
the 24 industries coincide with our intuition concerning traditional sectors that have comparatively little potential for dynamic efficiency gains (e.g. manufacture of tobacco products) and sectors that are more high-tech and have comparatively much potential for dynamic efficiency gains (e.g. manufacture of office machinery and computers). I find similar industry differences for the alternative measures of industry work autonomy (Table B.1 in the Appendix).

To provide a comparative perspective, I also present aggregated autonomy scores for the second least autonomous industry, after the manufacture of textiles (mining of coal and lignite, extraction of peat), and for some high-autonomy industries that also cannot be considered in the empirical analysis due to missing data (Table 2, Panel B).

Although employing cross-national data alleviates (benchmarking) biases, a remaining question is whether the measure of industry work autonomy is reliable. A particular concern is whether enough workers per industry have responded to the questionnaire item on work autonomy to render consistent results for the measured differences in industries' micro work environments. To check the reliability of the industry work autonomy measure, I triangulate measures of aggregate work autonomy across three different surveys (Table 3). These surveys have employed comparable but not identical questionnaire items to measure work autonomy. Moreover, data have been collected in a highly diverse group of countries, notably the US (GSS data), the Eurasian countries covered by the ESS data, and other countries from all over the world, including Japan, Mexico, Taiwan, South Africa and Dominican Republic (ISSP Research Group data). Notwithstanding, correlations between the various measures of aggregate work autonomy are strong, typically well above 0.70 .

These high correlations between aggregated autonomy scores constructed from different questionnaire items and data collected in countries with highly diverse institutional environments indicate that measures of industry work autonomy are, in fact, highly reliable, and not nearly as susceptible to measurement error as one might expect. Whether we use data from Eurasian countries, the US, or a varied set of countries worldwide, the industry differences in aggregate work autonomy that we find are highly similar, independent of the sample or the precise measure of work autonomy used. Still, reliability (as evidenced by the correlations between the three measures) tends to improve from having more individuallevel respondents on which to base the work autonomy score of an industry (see, for example, Panel A of Table 3 versus Panel B of Table 3). The most reliable results are obtained when there are at least 100 respondents per industry (Panel $\mathrm{C}$ of Table 3). In the empirical analysis, I therefore only include industries that meet this observational threshold. As it turns out, all industries depicted in Panel A of Table 2 meet this threshold (the lowest number of individual-level observations for any industry is 107).

\section{Estimating equation and data}

\subsection{Estimating equation}

I test the hypothesis that social trust interacts with industry work autonomy to affect countries' comparative advantage by estimating the following standard equation (Romalis, 2004):

$$
\ln \mathrm{R}_{\mathrm{ci}}=\beta_{0}+\beta_{1} \mathrm{a}_{\mathrm{i}} \mathrm{T}_{\mathrm{c}}+\beta_{2} \mathrm{~s}_{\mathrm{i}} \mathrm{H}_{\mathrm{c}}+\beta_{3} \mathrm{a}_{\mathrm{i}} \mathrm{H}_{\mathrm{c}}+\mathrm{u}_{\mathrm{i}}+\mathrm{U}_{\mathrm{c}}+\mathrm{Y}_{\mathrm{t}}+\varepsilon_{\mathrm{ci}} .
$$

In this equation, $\ln _{\mathrm{ci}}$ is the natural logarithm of the revealed comparative advantage (RCA) of country $c$ in industry $i, a_{i}$ is the measure of industry work autonomy, and $T_{c}$ is a 


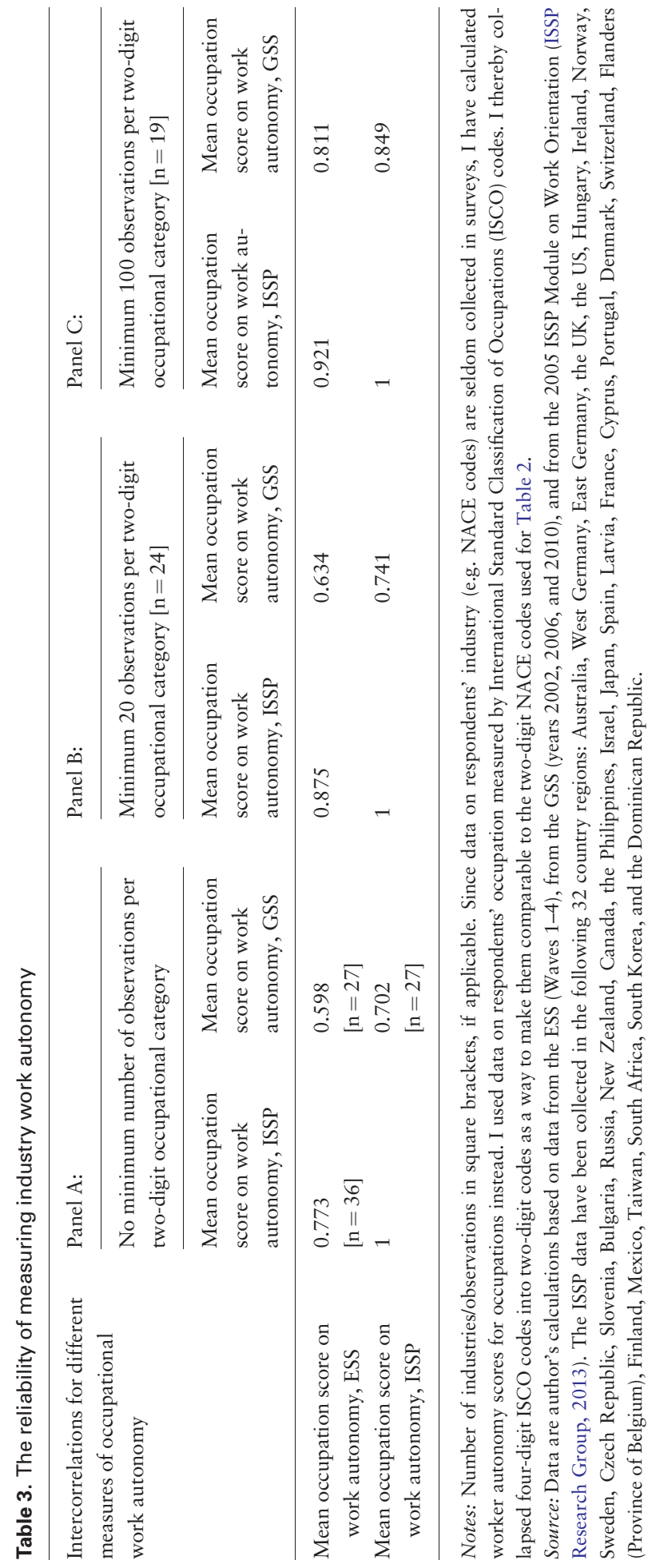


country's social trust norm. The key term in this equation is the interaction between industry work autonomy and social trust $\left(\mathrm{a}_{\mathrm{i}} \mathrm{T}_{\mathrm{c}}\right)$. By my hypothesis, a stronger social trust norm interacts with workplace organization to generate a comparative advantage in highautonomy industries. Hence, I expect a positive coefficient for this trust interaction.

A concern with the trust interaction is that both social trust $\left(\mathrm{T}_{\mathrm{c}}\right)$ and industry work autonomy $\left(\mathrm{a}_{\mathrm{i}}\right)$ proxy for another set of industry features and country factors that also interact to affect nations' comparative advantage in specific industries. Notably, social trust and industry work autonomy appear closely related to human capital, not least as firms seem more likely to grant autonomy to workers when these workers are better skilled and more highly educated (cf. Table 1). To make sure that we are, in fact, capturing the effect of social trust interacting with work autonomy to affect comparative advantage and not any effect due to human capital and skill intensity, eq. 1 includes two more interaction terms. The first of these interaction terms involves the high skill intensity of industries and countries' human capital endowment $\left(\mathrm{s}_{\mathrm{i}} \mathrm{H}_{\mathrm{c}}\right)$. The second additional interaction term involves industry work autonomy and again countries' human capital endowment $\left(\mathrm{a}_{\mathrm{i}} \mathrm{H}_{\mathrm{c}}\right)$. Together, these two additional interaction terms help rule out any spurious effects that otherwise might be captured by the trust interaction but that, in reality, derive from a country's human capital endowment or from an industry's level of skill intensity.

To complete the estimating equation, eq. 1 further includes industry $\left(\mathrm{u}_{\mathrm{i}}\right)$ and country fixed effects $\left(U_{c}\right)$, which is standard. Let me thereby emphasize that, following the standard of cross-country cross-industry analysis, the estimating equation does not include $a_{i}$ and $T_{c}$ separately. Instead, the estimating equation includes industry $\left(\mathrm{u}_{\mathrm{i}}\right)$ and country fixed effects $\left(U_{c}\right)$, which capture possible direct effects of $a_{i}$ (which are not unique to countries) and of $\mathrm{T}_{\mathrm{c}}$ (which are not unique to industries) as well as any other potential industry or country confounders (e.g. Nunn and Trefler, 2013; Ciccone and Papaioannou, 2016).

The model depicted in eq. 1 , meaning the model that includes the high skill intensity interaction and the human capital work autonomy interaction, is the baseline model of my empirical analysis. However, for my robustness checks, I also estimate models with other interaction terms added. Specifically, a possible concern is that the model in eq. 1, whilst controlling for human capital and skill intensity, still suffers an omitted variable bias. First, not yet considered, countries' formal institutional environment may also play a role (cf. Levchenko, 2007; Nunn, 2007). Hence, to rule out any spurious effect that might derive from not controlling for quality of formal institutions, I also consider a model that adds the interaction between institutional quality of country $c\left(Q_{c}\right)$ and industry work autonomy $\left(a_{i}\right)$ to the baseline model depicted in eq. 1. $^{7}$ Second, I want to rule out that any effect found might be due to higher social trust, somehow, favouring industries that are more dependent on external finance (cf. Manova, 2008, 2013). Hence, I also extend eq. 1 to consider the

7 Still, it may be noted that, from a theoretical perspective, the interaction between formal institutional arrangements and industry work autonomy is likely to be less important than the interaction between trust and industry work autonomy. The reason is that the nature of the concept of work autonomy means that, almost by definition, it does not involve any formal contract or agreement between the principal and the agent that could be subject to enforcement through formal institutions. Consistent with this observation, Van Hoorn (2013) finds that trust is more strongly related to work autonomy than is institutional quality. 
interaction between social trust $\left(\mathrm{T}_{\mathrm{c}}\right)$ and an industry benchmark of reliance on external finance $\left(f_{i}\right)$.

\subsection{Data}

4.2.1 Dependent variable My measure of comparative advantage is Balassa's (1965) well-known index of RCA. This index defines the RCA of industry $\mathrm{i}$ in country $\mathrm{c}$ as: $\mathrm{RCA}_{\mathrm{ic}}=\left(\mathrm{X}_{\mathrm{ic}} / \mathrm{X}_{\mathrm{c}}\right) /\left(\mathrm{X}_{\mathrm{i}} / \mathrm{X}\right)$, where $\mathrm{X}_{\mathrm{ic}}$ denotes exports of industry $\mathrm{i}$ in country $\mathrm{c}, \mathrm{X}_{\mathrm{c}}$ denotes total exports by country $\mathrm{c}$ across all industries, $\mathrm{X}_{\mathrm{i}}$ denotes total exports of industry $\mathrm{i}$ in all other countries combined (specifically all other OECD countries), and X denotes total exports by all other countries combined. The underlying data are thereby converted to a common currency. Data come from the OECD Database for Structural Analysis (known as the STAN database) with conversion to a common currency using US\$ GDP Purchasing Power Parities (OECD, 2010). As the RCA data in STAN cover the years 1999-2008, I am able to calculate industries' average comparative advantage over multiple years, which reduces measurement error due to idiosyncratic shocks (for example fluctuations in oil prices affecting Norway's RCA or disadvantage in certain industries).

I am able to match industry autonomy scores to data on RCA for 24 industries from the STAN database (see Table 2). To be sure, the STAN database covers more industries. However, these are not at the two-digit NACE level, notably because they collapse RCA scores for two or more two-digit industries into one. For example, NACE industries 13 (Mining of metal ores) and 14 (Other mining) do not have distinct RCA scores in the STAN database only a single score covering both these industries. I therefore cannot match these RCA data with the industry work autonomy measure constructed in Section 3, as this measure concerns only distinct two-digit industries. Implication is that the analysis below does not consider all industries in the countries in my sample. Note, though, that this lack of industry data does not affect the RCA measure itself, which is still constructed involving the exports of all countries in all industries. As data on Luxembourg are missing, the STAN database has data available for 29 countries, all OECD members. The empirical analyses thus concern a total of $24 \times 29=696$ observations. Table B. 1 in the Appendix presents descriptive statistics for the industries included in the analysis. Table B.2 lists the countries in the sample.

4.2.2 Key independent variables Equation 1 has two key independent variables. The first is the measure of industry work autonomy described in the previous section. The second is social trust. I use the measure of trust available from the European Value Study (EVS) and World Values Survey (WVS) (EVS-WVS, 2006; WVS Association, 2009). This canonical measure derives from the dummy-coded questionnaire item asking respondents whether they find 'most people can be trusted' (score of 1 ) or 'you need to be very careful in dealing with people' (score of 0 ). The EVS-WVS has collected trust data in different waves, starting in 1981. I follow the standard procedure in the literature, which is to calculate country trust norms by aggregating responses from the various waves, meaning that for most countries I include responses from more than one wave. This procedure matches the conception of social trust as a stable cultural trait of societies with deep roots (Guiso et al., 2008). Table C. 1 in the Appendix presents scores on the trust measure for the 29 countries in the sample. To address potential reverse causality, from comparative advantage to social trust, I also construct an alternative trust indicator that provides a more direct measure of 
the cultural component of social trust and is untainted by nations' RCA. I describe the construction of this indicator and its rationale in detail in the next section.

\subsubsection{Other main independent variables Equation 1 contains two other important inde-} pendent variables, one at the country level and one at the industry level. At the country level, I measure human capital endowment using data on average years of schooling from the United Nations Development Programme (UNDP) statistical database (2014). This database provides a measure of countries' average years of schooling, typically at five-year intervals. To match the period for calculating average RCA, I use data for the year 2005.

At the industry level, I measure the intensity with which an industry uses high-skilled labour in the same way as I measure industry work autonomy. This means that I aggregate individual-level data from the ESS. I again draw on the first four waves of the ESS, and construct an individual-level dummy variable that gets a score of 1 if the respondent has had at least some tertiary education (ISCED classification V1 or higher; see Panel C of Table 1) and 0 otherwise. Aggregating this dummy variable at the industry level renders percentage scores denoting each industry's level of high skill intensity. Percentage scores can range from $2.97 \%$ (agriculture, hunting, related service activities) to $20.9 \%$ (manufacture of office machinery and computers). Following the same procedure as just outlined, I also construct an alternative measures of industries' skill intensity that refers to average years of education. I use this alternative measure to assess the robustness of my baseline results. Table B.1 presents details including the full set of industry scores.

Finally, as indicated, my robustness checks also involve additional independent variables, specifically institutional quality at the country level and reliance on external finance at the industry level. To measure the quality of formal institutions in a country, I use the rule of law index from the World Bank Worldwide Governance Indicators project (World Bank, 2015). As for human capital, I use data for the year 2005. To measure an industry's reliance on external finance, I use data from the 2012/2013 round of the EBRD-World Bank Business Environment and Enterprise Performance Survey (BEEPS V). This survey asks firms in a set of emerging economies whether they have a 'line of credit or a loan from a financial institution?' I subsequently calculate the industry benchmark by looking at the percentage of firms in a two-digit industry that responded yes to this question.

\section{Empirical results}

\subsection{Baseline results}

Table 4 presents the baseline results, obtained by estimating different specifications of eq. 1. Results reveal a strong and statistically highly significantly positive interaction between social trust and workplace organization (Model 1), which confirms my hypothesis that societies with stronger trust norms have a comparative advantage in industries characterized by more autonomous work environments, and vice versa. This relationship between social trust, workplace organization, and industry comparative advantage remains when controlling for confounding effects associated with countries' human capital endowment and the intensity with which industries use high-skilled labour in their production processes (Models 2-4). The coefficients for the interaction terms involving human capital both have the expected sign and are statistically significant at usual levels when included separately (Models 2-3). Including both interaction terms simultaneously, however, neither of the 
Table 4. Work autonomy, social trust, and revealed comparative advantage

\begin{tabular}{lcccc}
\hline & $(1)$ & $(2)$ & $(3)$ & $(4)$ \\
\hline Social trust interaction $\left(\mathrm{a}_{\mathrm{i}} \mathrm{T}_{\mathrm{c}}\right)$ & $1.32 * * *$ & $1.12 * * *$ & $0.984 * * *$ & $0.984 * * *$ \\
& $(0.205)$ & $(0.227)$ & $(0.240)$ & $(0.240)$ \\
High skill intensity interaction $\left(\mathrm{s}_{\mathrm{i}} \mathrm{H}_{\mathrm{c}}\right)$ & - & $0.453 *$ & - & 0.205 \\
& & $(0.231)$ & & $(0.361)$ \\
Human capital work autonomy interaction $\left(\mathrm{a}_{\mathrm{i}} \mathrm{H}_{\mathrm{c}}\right)$ & - & - & $0.770 *$ & 0.566 \\
& & & $(0.311)$ & $(0.494)$ \\
Country fixed effects & Yes & Yes & Yes & Yes \\
Industry fixed effects & Yes & Yes & Yes & Yes \\
No. of obs. & 696 & 696 & 696 & 696 \\
$\mathrm{R}^{2}$ & 0.276 & 0.279 & 0.280 & 0.281 \\
\hline
\end{tabular}

Notes: The dependent variable is the natural logarithm of revealed comparative advantage of country c in industry i (see eq. 1). Sample covers 24 industries (two-digit NACE) in 29 countries. Standard errors (in parentheses) are robust standard errors. Coefficients are standardized beta coefficients. $* * \mathrm{p}<0.01, * * \mathrm{p}<0.05$, and $* \mathrm{p}<0.10$.

terms is statistically significant at usual levels, whilst the social trust interaction is (Model 4).

More important than statistical significance, the social trust interaction is also highly significant in terms of effect size. As I report standardized beta coefficients, we can easily ascertain that a one standard deviation increase in the trust interaction is associated with an increase in RCA of about one standard deviation, ceteris paribus. Naturally, the magnitude of the coefficient for the trust interaction decreases a bit when adding control variables. This is as expected, however, given that social trust is recognized to have a positive effect on human capital accumulation (Coleman, 1988). In fact, there is a case to be made that Models 2-4 are overfitted because social trust has a causal effect on human capital. In terms of the aim of this paper, these baseline results provide strong support for the idea that industries characterized by highly autonomous micro work environments flourish in hightrust societies, in turn resulting in predictable patterns of comparative advantage at the macro level.

\subsection{Robustness checks}

To assess the robustness of the baseline results presented in Table 4, I perform several additional checks. I start with a very simple and general check that explicitly deals with outliers. For this purpose, I re-estimate eq. 1 (Model 4 in Table 4) using quantile regressions and a sample that excludes any observations that score more than two standard deviations below or above the mean on either RCA $\left(\operatorname{lnR}_{\mathrm{ci}}\right)$ or on the trust interaction $\left(\mathrm{a}_{\mathrm{i}} \mathrm{T}_{\mathrm{c}}\right)$. I do not report detailed results here, but these are available on request. In all cases, the coefficient for the interaction between social trust and industry work autonomy remains strongly positive and highly statistically significant.

As indicated in the previous section, to address potential benchmarking biases (Nunn and Trefler, 2013; Ciccone and Papaioannou, 2016), I check the robustness of my baseline results to the measure of industry work autonomy used. Results show that the relationship between the trust interaction and comparative advantage continues to hold when using the 
Table 5. Robustness check for alternative measures of industry work autonomy, an alternative measure of industry skill intensity, and different samples

\begin{tabular}{|c|c|c|c|c|c|}
\hline & \multicolumn{2}{|c|}{$\begin{array}{l}\text { Alternative industry } \\
\text { work autonomy } \\
\text { measure, below-average } \\
\text { work autonomy sample }\end{array}$} & \multicolumn{2}{|c|}{$\begin{array}{l}\text { Alternative industry } \\
\text { work autonomy measure, } \\
\text { above-average work } \\
\text { autonomy sample }\end{array}$} & \multirow{2}{*}{$\begin{array}{l}\text { Alternative } \\
\text { measure of } \\
\text { high skill } \\
\text { intensity }\left(\mathrm{s}_{\mathrm{i}}\right) \\
\text { (9) }\end{array}$} \\
\hline & $(5)$ & (6) & (7) & (8) & \\
\hline $\begin{array}{l}\text { Social trust interaction with } \\
\text { industry autonomy meas- } \\
\text { ure based on below-aver- } \\
\text { age work autonomy } \\
\text { sample }\left(\mathrm{a}_{\mathrm{i}} \mathrm{T}_{\mathrm{c}}\right)\end{array}$ & $\begin{array}{l}0.830 * * * \\
(0.290)\end{array}$ & - & - & - & - \\
\hline $\begin{array}{l}\text { Social trust interaction with } \\
\text { industry autonomy meas- } \\
\text { ure based on above-aver- } \\
\text { age work autonomy } \\
\text { sample }\left(\mathrm{a}_{\mathrm{i}} \mathrm{T}_{\mathrm{c}}\right)\end{array}$ & - & - & $\begin{array}{l}0.770 * * \\
(0.305)\end{array}$ & - & - \\
\hline Social trust interaction $\left(\mathrm{a}_{\mathrm{i}} \mathrm{T}_{\mathrm{c}}\right)$ & - & $\begin{array}{l}1.04 * * * \\
(0.260)\end{array}$ & - & $\begin{array}{l}0.738 * * * \\
(0.225)\end{array}$ & $\begin{array}{l}0.984 * * * \\
(0.240)\end{array}$ \\
\hline $\begin{array}{l}\text { High skill intensity inter- } \\
\text { action }\left(\mathrm{s}_{\mathrm{i}} \mathrm{H}_{\mathrm{c}}\right)\end{array}$ & $\begin{array}{c}0.499 \\
(0.315)\end{array}$ & $\begin{array}{c}0.031 \\
(0.386)\end{array}$ & $\begin{array}{l}0.585 * \\
(0.333)\end{array}$ & $\begin{array}{c}0.084 \\
(0.460)\end{array}$ & - \\
\hline $\begin{array}{l}\text { General skill intensity inter- } \\
\text { action }\left(\mathrm{s}_{\mathrm{i}} \mathrm{H}_{\mathrm{c}}\right)\end{array}$ & - & - & - & - & $\begin{array}{c}0.487 \\
(0.507)\end{array}$ \\
\hline $\begin{array}{l}\text { Human capital autonomy } \\
\text { interaction with industry } \\
\text { autonomy measure based } \\
\text { on below-average work au- } \\
\text { tonomy sample }\left(\mathrm{a}_{\mathrm{i}} \mathrm{H}_{\mathrm{c}}\right)\end{array}$ & $\begin{array}{c}0.230 \\
(0.448)\end{array}$ & - & - & - & - \\
\hline $\begin{array}{l}\text { Human capital autonomy } \\
\text { interaction with industry } \\
\text { autonomy measure based } \\
\text { on above-average work au- } \\
\text { tonomy sample }\left(\mathrm{a}_{\mathrm{i}} \mathrm{H}_{\mathrm{c}}\right)\end{array}$ & - & - & $\begin{array}{l}0.901 * \\
(0.518)\end{array}$ & - & - \\
\hline $\begin{array}{l}\text { Human capital autonomy } \\
\text { interaction }\left(\mathrm{a}_{\mathrm{i}} \mathrm{H}_{\mathrm{c}}\right)\end{array}$ & - & $\begin{array}{c}0.875 \\
(0.543)\end{array}$ & - & $\begin{array}{l}1.21 * * \\
(0.592)\end{array}$ & $\begin{array}{c}0.466 \\
(0.459)\end{array}$ \\
\hline Country fixed effects & Yes & Yes & Yes & Yes & Yes \\
\hline Industry fixed effects & Yes & Yes & Yes & Yes & Yes \\
\hline No. of obs. & 609 & 609 & 609 & 609 & 696 \\
\hline No. of countries & 29 & 29 & 29 & 29 & 29 \\
\hline No. of industries & 21 & 21 & 21 & 21 & 24 \\
\hline $\mathrm{R}^{2}$ & 0.2563 & 0.2707 & 0.3347 & 0.3359 & 0.2816 \\
\hline
\end{tabular}

Notes: The dependent variable is the natural logarithm of revealed comparative advantage of country c in industry i. The industries that have been dropped differ for the two alternative measures of industry work autonomy (see Table B.2 in Appendix B). Standard errors (in parentheses) are robust standard errors. Coefficients are standardized beta coefficients. $* * \mathrm{p}<0.01, * \mathrm{p}<0.05$, and $* \mathrm{p}<0.10$. 
Table 6. Controlling for institutional quality and industries' dependence on external finance

\begin{tabular}{|c|c|c|c|c|}
\hline & \multirow{2}{*}{$\begin{array}{l}\text { Quality of formal } \\
\text { institutions }\left(Q_{c}\right) \\
\qquad(10)\end{array}$} & \multicolumn{2}{|c|}{$\begin{array}{l}\text { External finance } \\
\text { dependence }\left(f_{i}\right)\end{array}$} & \multirow{2}{*}{$\begin{array}{l}\text { Quality of formal } \\
\text { institutions \& } \\
\text { Dependence on } \\
\text { external finance } \\
\text { (13) }\end{array}$} \\
\hline & & (11) & (12) & \\
\hline Social trust interaction $\left(\mathrm{a}_{\mathrm{i}} \mathrm{T}_{\mathrm{c}}\right)$ & $\begin{array}{l}0.946 * * * \\
(0.299)\end{array}$ & $\begin{array}{l}1.08 * * * \\
(0.254)\end{array}$ & $\begin{array}{l}1.02 * * * \\
(0.244)\end{array}$ & $\begin{array}{l}1.04 * * * \\
(0.309)\end{array}$ \\
\hline Institutional quality interaction $\left(\mathrm{a}_{\mathrm{i}} \mathrm{Q}_{\mathrm{c}}\right)$ & $\begin{array}{c}0.053 \\
(0.373)\end{array}$ & - & - & $\begin{array}{c}0.065 \\
(0.392)\end{array}$ \\
\hline $\begin{array}{l}\text { Dependence on external finance } \\
\text { interaction }\left(f_{i} T_{c}\right)\end{array}$ & - & $\begin{array}{c}0.158 \\
(0.142)\end{array}$ & - & $\begin{array}{c}0.158 \\
(0.142)\end{array}$ \\
\hline High skill intensity interaction $\left(\mathrm{s}_{\mathrm{i}} \mathrm{H}_{\mathrm{c}}\right)$ & $\begin{array}{c}0.205 \\
(0.361)\end{array}$ & $\begin{array}{r}-0.263 \\
(0.483)\end{array}$ & $\begin{array}{r}-0.383 \\
(0.465)\end{array}$ & $\begin{array}{l}-0.263 \\
(0.484)\end{array}$ \\
\hline $\begin{array}{l}\text { Human capital work autonomy } \\
\text { interaction }\left(\mathrm{a}_{\mathrm{i}} \mathrm{H}_{\mathrm{c}}\right)\end{array}$ & $\begin{array}{c}0.560 \\
(0.510)\end{array}$ & $\begin{array}{l}1.22 * \\
(0.626)\end{array}$ & $\begin{array}{l}1.35 * * \\
(0.603)\end{array}$ & $\begin{array}{l}1.21 * \\
(0.642)\end{array}$ \\
\hline Country fixed effects & Yes & Yes & Yes & Yes \\
\hline Industry fixed effects & Yes & Yes & Yes & Yes \\
\hline No. of obs. & 696 & 609 & 609 & 609 \\
\hline No. of countries & 29 & 29 & 29 & 29 \\
\hline No. of industries & 24 & 21 & 21 & 21 \\
\hline $\mathrm{R}^{2}$ & 0.2808 & 0.3372 & 0.3356 & 0.3373 \\
\hline
\end{tabular}

Notes: The dependent variable is the natural logarithm of revealed comparative advantage of country c in industry i. Standard errors (in parentheses) are robust standard errors. Coefficients are standardized beta coefficients. ** $\mathrm{p}<0.01, * \mathrm{p}<0.05$, and $* \mathrm{p}<0.10$.

two alternative measures of industry work autonomy (Models 5 and 7 in Table 5). Estimates are less precise, but this is as expected given that the two alternative measures are based on less information (i.e. on fewer individual-level observations) than the original measure of industry work autonomy and, therefore, have more measurement error. In terms of attenuating or amplifying bias, using the two alternative measures of industry work autonomy renders both a larger and a smaller coefficient for the trust interaction compared to models that concern the same sample but employ my original measure of industry work autonomy (Model 5 versus Model 6 and Model 7 versus Model 8). Being in between, I conclude that the original industry work autonomy measure is able to render estimates that are largely unbiased, neither over- nor understating the extent to which social trust and workplace organization interact to shape cross-country patterns of comparative advantage.

Expanding on the industry benchmarking check, I also assess whether the baseline results are robust to using the alternative measure of industry skill intensity that I have constructed. Again, results are largely the same as before (Model 9 in Table 5 versus Model 4 in Table 4).

Finally, I extend the baseline model to control for quality of formal institutions and industries' dependence on external finance respectively (Table 6). In all cases, the estimated coefficient for the interaction between trust and industry work autonomy remains strongly and statistically significantly positive. This finding extends to the model that considers both institutional quality and dependence on external finance simultaneously (Model 13). 


\subsection{Dealing with potential reverse causality}

Although the above results are suggestive of social trust causally interacting with workplace organization to affect industry comparative advantage, without additional evidence we cannot rule out completely that there is reverse causality between social trust and countries' comparative advantage in certain industries. Indeed, the positive relationship between the trust interaction and RCA would also be consistent with a process in which countries that have a comparative advantage in high-autonomy industries tend to develop societal norms that provide further support to the workings of these industries. Ordinarily, one would deal with this endogeneity problem via instrumental variables analysis. Instrumenting for social trust is notoriously problematic, however, as the factor(s) that could instrument for social trust typically also instrument for other determinants of comparative advantage, thus violating the exclusion restriction (e.g. Algan and Cahuc, 2013).

My solution is to construct an indicator of social trust that captures the stable cultural component of trust, meaning that this indicator is as much as possible independent of economic and institutional influences in general and of industry comparative advantage in particular. The way I go about constructing this indicator is to use trust levels reported by migrants to proxy for social trust in these migrants' countries of ancestry (cf. Algan and Cahuc, 2010). Migrants are a special group, as they can still harbour their culturally determined trust attitudes but are not affected by the reigning economic and institutional conditions in their ancestry countries, simply because they no longer reside in these countries. Accordingly, the remaining country-of-ancestry effects are a direct reflection of the cultural component of social trust, whilst the only economic or institutional influences on migrants' trust levels are due to the economic and institutional conditions in their destination countries. The data that I use to construct this indicator of the cultural component of social trust come from the ESS (Waves 1-5) and concern first and second generation

Table 7. The causal effect of social trust on comparative advantage in high-/low-autonomy industries

\begin{tabular}{lcc}
\hline Social trust interaction $\left(\mathrm{a}_{\mathrm{i}} \mathrm{T}_{\mathrm{c}}\right)$ & $0.758^{* * * *}$ & $0.607^{* * *}$ \\
High skill intensity interaction $\left(\mathrm{s}_{\mathrm{i}} \mathrm{H}_{\mathrm{c}}\right)$ & $(0.268)$ & $(0.268)$ \\
& 0.205 & 0.205 \\
Human capital work autonomy interaction $\left(\mathrm{a}_{\mathrm{i}} \mathrm{H}_{\mathrm{c}}\right)$ & $(0.360)$ & $(0.386)$ \\
& 0.738 & 0.630 \\
Institutional quality interaction $\left(\mathrm{a}_{\mathrm{i}} \mathrm{Q}_{\mathrm{c}}\right)$ & $(0.527)$ & $(0.563)$ \\
& - & 0.335 \\
Country fixed effects & & $(0.293)$ \\
Industry fixed effects & Yes & Yes \\
No. of obs. & Yes & Yes \\
$\mathrm{R}^{2}$ & 696 & 696 \\
\end{tabular}

Notes: The dependent variable is the natural logarithm of revealed comparative advantage of country c in industry i. Since the trust measure used for this table is itself generated using regression analysis, standard errors are robust standard errors that are bootstrapped using 1,000 repetitions. Coefficients are standardized beta coefficients. *** $\mathrm{p}<0.01, * \mathrm{p}<0.05$, and $* \mathrm{p}<0.10$. 
migrants. The Appendix presents a detailed description of the construction of the indicator. ${ }^{8}$

I use the alternative social trust indicator to re-estimate the baseline model (Model 4). The trust interaction remains highly statistically significant and sizeable, also when I further control for institutional quality (cf. Model 10) (Table 7). Overall, I conclude that social trust indeed causally interacts with workplace organization to shape cross-country patterns of comparative advantage.

\section{Conclusion}

The idea of specialization through the division of labour is one of the most powerful ideas in economics. Trust subsequently is widely recognized for its role as a social lubricant, fostering mutually beneficial exchange and thereby sustaining higher levels of specialization. Moreover, many studies show that social trust is a robust determinant of various macroeconomic outcomes. What is lacking, however, is a specific pathway that can take us from the micro logic of trust as a promoter of economic exchange to the macro evidence on the effect of social trust on societies as a whole. In this paper, I have sought to develop such a channel, working on pinning down how social trust may matter for the interaction between economic actors at the micro level in a way that affects economies in the aggregate. Specifically, my empirical analysis indicates that social trust interacts with workplace organization to determine countries' comparative advantage and shape cross-country patterns of comparative advantage.

The paper's broader contribution lies in bringing together two important literatures that so far have been largely unconnected. Significant advances have been made in the literature on the effect of workplace organization and organizational design on firm performance (e.g. Bloom et al., 2014) and in the literature on the effect of informal institutions, particularly social trust, on macroeconomic outcomes (Algan and Cahuc, 2013). Unfortunately, these developments have been happening largely independent from each other. From this perspective, the connection that I have sought to develop in this paper can be seen to act as a lynchpin that brings the two literatures together. A most fruitful avenue for future research is to establish further lynchpins as a way of incorporating other types of microeconomic insights in the comparative study of economies.

Future research could also address some of the limitations of the paper's empirical analysis. Most importantly, data availability has kept me from analysing a global sample of countries, analysing a sample of OECD countries instead. The narrow nature of this sample, covering only countries in relatively advanced stages of economic and institutional maturity, has likely biased my estimates against finding evidence that social trust interacts with workplace organization to affect the comparative advantage of nations. Nevertheless, we need follow-up research both to generalize the idea of linking microeconomic insights to the macroeconomic consequences of (in)formal institutions and to generalize my empirical evidence to globally representative samples.

8 Compared to the US GSS data that Algan and Cahuc (2010) use, the ESS data are much richer, allowing me to construct this trust indicator for the largest share of countries in my sample (and, with an eye to future research, many more countries that are not in my sample). 


\section{Supplementary material}

The Appendix for this paper is available online at the OUP website. All data used are publicly available. Data files and the SPSS syntax and Stata Do files that allow the regression results of this paper to be reproduced from these data sources are also available on the OUP website.

\section{Acknowledgements}

The author wishes to thank Mariko Klasing for invaluable feedback. Helpful comments from two anonymous referees, the editor, seminar participants at the University of Groningen and the Hanse Institute for Advanced Study, as well as from participants at the 2013 ZEW workshop on the Impact of Human Resource Management are also gratefully acknowledged. Part of the work reported on in this paper was done while the author was affiliated with the University of Groningen.

\section{References}

Algan, Y. and Cahuc, P. (2010) Inherited trust and growth, American Economic Review, 100, 2060-92.

Algan, Y. and Cahuc, P. (2013) Trust, institutions, and development, Annual Review of Economics, 5, 521-49.

Arrow, K.J. (1972) Gifts and exchanges, Philosophy and Public Affairs, 1, 343-62.

Balassa, B. (1965) Trade liberalization and revealed comparative advantage, The Manchester School of Economic and Social Studies, 33, 99-123.

Bazzi, S. and Clemens, M.A. (2013) Blunt instruments: avoiding common pitfalls in identifying the causes of economic growth, American Economic Journal: Macroeconomics, 5, 152-86.

Becker, G.S. and Murphy, K.M. (1992) The division of labor, coordination costs, and knowledge, Quarterly Journal of Economics, 107, 1137-60.

Beugelsdijk, S., De Groot, H.L., and Van Schaik, A.B. (2004) Trust and economic growth: a robustness analysis, Oxford Economic Papers, 56, 118-34.

Bloom, N., Lemos, R., Sadun, R., Scur, D., and Van Reenen, J. (2014) The new empirical economics of management, Journal of the European Economic Association, 12, 835-76.

Bloom, N., Sadun, R., and Van Reenen, J. (2012) The organization of firms across countries, Quarterly Journal of Economics, 127, 1663-705.

Ciccone, A. and Papaioannou, E. (2016) Estimating cross-industry cross-country interaction models using benchmark industry characteristics, National Bureau of Economic Research Working Paper No. 22368, NBER, Cambridge, MA.

Cingano, F. and Pinotti, P. (2012) Trust, firm organization and the structure of production, Dondena Working Paper No. 53, Università Bocconi.

Coleman, J.S. (1988) Social capital in the creation of human capital, American Journal of Sociology, 94, 95-120.

Cronbach, L.J. and Meehl, P.E. (1955) Construct validity in psychological tests, Psychological Bulletin, 52, 281-302.

European Values Study Group and World Values Survey Association. (2006) European and World Values Surveys four-wave integrated data file, 1981-2004 v.20060423, Aggregate File Producer: ASEP/JDS, Madrid.

Fukuyama, F. (1995) Trust: The Social Virtues and the Creation of Prosperity, Hamish Hamilton, London.

Gambetta, D. (ed.) (1988) Trust: Making and Breaking Cooperative Relations, Basil Blackwell, Oxford. 
Guiso, L., Sapienza, P., and Zingales, L. (2008) Social capital as good culture, Journal of the European Economic Association, 6, 295-320.

Gur, N. and Bjørnskov, C. (2016) Trust and delegation: theory and evidence, Journal of Comparative Economics, doi: 10.1016/j.jce.2016.02.002.

Hackman, R.J. and Oldham, G.R. (1975) Development of the Job Diagnostic Survey, Journal of Applied Psychology, 60, 159-70.

Hofstede, G. (2001) Culture's Consequences: Comparing Values, Behaviors, Institutions, and Organizations Across Nations, 2nd edition, Sage, Thousand Oaks, CA.

ISSP Research Group. (2013) International Social Survey Programme: Work Orientation III - ISSP 2005, GESIS Data Archive, Cologne. ZA4350 Data file Version 2.0.0, doi:10.4232/1.11648.

Jermier, J.M. and Michaels, C.E. (2001) Autonomy at work, in N.J. Smelser and P.B. Baltes (eds) International Encyclopedia of Social and Behavioral Sciences, Pergamon, Oxford.

Jowell, R. and Central Co-ordinating Team. (2007) European Social Survey 2006/2007: Technical Report, Centre for Comparative Social Surveys, London. Data archived by the Norwegian Social Science Data Services.

Levchenko, A.A. (2007) Institutional quality and international trade, Review of Economic Studies, 74, 791-819.

Manova, K. (2008) Credit constraints, equity market liberalizations and international trade, Journal of International Economics, 76, 33-47.

Manova, K. (2013) Credit constraints, heterogeneous firms, and international trade, Review of Economic Studies, 80, 711-44.

Nunn, N. (2007) Relationship-specificity, incomplete contracts, and the pattern of trade, Quarterly Journal of Economics, 122, 569-600.

Nunn, N. and Trefler, D. (2013) Domestic institutions as a source of comparative advantage, NBER Working Paper No. w18851, Cambridge, MA.

OECD. (2010) Database for Structural Analysis (STAN), STAN Archives, STAN Indicators 2009. Accessed 12 June 2013.

Oldham, G.R. and Hackman, J.R. (2010) Not what it was and not what it will be: the future of job design research, Journal of Organizational Behavior, 31, 463-79.

Romalis, J. (2004) Factor proportions and the structure of commodity trade, American Economic Review, 94, 67-97.

Smith, A. (1776) [2003] An Inquiry into the Nature and Causes of the Wealth of Nations, Bantam, New York.

Smith, T.W., Marsden, P., Hout, M., and Kim, J. (2013) General Social Surveys, 1972-2012 [machine-readable data file], National Opinion Research Center [producer], Chicago, IL.

Tabellini, G. (2008) Institutions and culture, Journal of the European Economic Association, 6, 255-94.

UNDP (2014) Human Development Reports, mean years of schooling (of adults) (years). Available at: http://hdr.undp.org/en/content/mean-years-schooling-adults-years (accessed 14 July 2014).

Van Hoorn, A. (2013) Trust and management: explaining cross-national differences in work autonomy, SOM Research Report No. 13015-GEM, University of Groningen.

Van Hoorn, A. (2016) How much does job autonomy vary across countries and other extraorganizational contexts?, International Journal of Human Resource Management, doi: 10.1080/09585192.2016.1192052.

World Bank. (2015) Worldwide Governance Indicators, 1996-2014, Available at: http://info. worldbank.org/governance/wgi (accessed 17 April 2016).

World Values Survey Association. (2009) World Values Survey 1981-2008 Official Aggregate v.20090901, Aggregate File Producer ASEP/JDS, Madrid. 